\title{
Redes Sociais na Internet: Considerações Iniciais ${ }^{1}$
}

\author{
Raquel da Cunha Recuero ${ }^{2}$ \\ Universidade Federal do Rio Grande do Sul \\ Universidade Católica de Pelotas \\ raquelrecuero@terra.com.br
}

\begin{abstract}
Resumo: O presente artigo discute a insuficiência dos modelos de redes igualitárias, pequenos mundos e redes sem escalas para dar conta do problema das redes sociais estabelecidas através da comunicação mediada por computador
\end{abstract}

\begin{abstract}
The present article discusses the insufficience of egalitarian networks model, small world model and scalefree model to explain social networks established through computer mediated-communication.
\end{abstract}

Resumé: L'article suivant discute la l'insuffisance des modèles de réseaux égalitaire, petits mondes et 'scale-free' pour expliquer les réseaux sociaux établis par la communication mediatisée par ordinateur.

Resumen: El presente artículo discute los problemas del modelo igualitario de las redes, del modelo de mundos pequeños y del modelo 'scale-free' para explicar las redes sociales establecidas con la comunicación por la computadora.

Palavras-Chaves: redes sociais, orkut, weblogs.

Key-words: social networks, orkut, weblogs.

Mots-Clés: réseaux sociaux, orkut, weblogs.

Palabras-claves: redes sociales, orkut, weblogs.

\footnotetext{
${ }^{1}$ Trabalho apresentado no Núcleo de Pesquisa (NP-08) de Tecnologias da Comunicação e Informação do do IV Encontro dos Núcleos de Pesquisa da XXVII INTERCOM, em setembro de 2004, em Porto Alegre/RS.

2 Doutoranda em Comunicação e Informação pelo PPGCOM/UFRGS, mestre em Comunicação e Informação pelo PPGCOM/UFRGS, professora da Escola de Comunicação da Universidade Católica de Pelotas (ECOS/UCPEL), pesquisadora vinculada a núcleos de pesquisa em comunicação da UFRGS e da UCPel.
} 


\section{Introdução}

$\mathrm{O}$ interesse no estudo de redes complexas ${ }^{3}$ permeia todo o século XX. Iniciado pelas ciências exatas, notadamente matemáticos e físicos trouxeram as maiores constribuições para o estudo das redes, que depois foram absorvidas pela sociologia, na perspectiva da análise estrutural das redes sociais.

O presente artigo busca trazer ao debate os modelos de estudo das redes complexas e sua aplicabilidade para as redes sociais na Internet Trabalhando a partir da perspectiva da análise estrutural das redes sociais e dos modelos de Barabási e Albert, Watts e Strogatz e Erdös e Rényi, o artigo busca discutir as implicações de suas aplicações na comunicação mediada por computador, bem como um possível diálogo entre a perspectiva sociológica e a perspectiva matemática desses autores. Resultado de um estudo exploratório que trabalha com a observação empírica de possíveis redes sociais na internet no Orkut, nos weblogs e nos fotologs, o artigo trabalha com exemplos buscando clarificar o debate e demonstrando pontos fortes e fracos nessa aplicação da teoria.

\section{O Paradigma da Análise Estrutural das Redes Sociais}

Os primeiros passos da teoria das redes encontram-se principalmente nos trabalhos do matemático Ëuler4 que criou o primeiro teorema da teoria dos grafos. Um grafo é uma representação de um conjunto de nós conectados por arestas que, em conjunto, formam uma rede. Em cima dessa nova idéia,

\footnotetext{
3 De acordo com Scharnhorst (2003), as redes complexas podem ser descritas de acordo com Leydesdorff (1994) como "auto-organizações que podem ser distintas em termos de estágios de desenvolvimento de redes cada vez mais complexas." Tradução da autora: "selforganization can be distinguished in terms of developmental stages of increasingly complex networks." (Leydesdorff, 1994).

4 Ëuler trabalho na solução de seu enigma das pontes para acesso da cidade prussiana de Königsberg por volta do seculo XVIII. O problema consistia em atravessas todas as sete pontes que conectavam a cidade sem passar duas vezes pela mesma ponte. Ele demonstrou que isso não poderia ser feito através de um teorema em que tratava as pontes como arestas e os lugares que deveriam ser conectados como nós.
} 
vários estudiosos dedicaram-se ao trabalho de compreender quais eram as propriedades dos vários tipos de grafos e como se dava o processo de sua construção, ou seja, como seus nós se agrupavam .([Buchanan, 2002], [Barabási, 2003] e [Watts, 2003, 1999]) Essa forma de percepção das coisas como redes seria crucial para a compreensão das relações complexas do mundo ao nosso redor.

Na sociologia, a teoria dos grafos é uma das bases do estudo das redes sociais, ancorado na chamada Análise Estrutural (Degenne e Forsé, 1999), proveniente das décadas de 60 e 705, que dedica especial atenção à análise das estruturas sociais. A importância dessa abordagem está, fundamentalmente, na sua origem sistêmica (Wellman, 1999 e Scharnhorst, 2003), berço da maioria das teorias que procuram descartar o cartesianismo da análise da parte, buscando a análise do todo, afirmando que este possui propriedades que vão além da mera soma de suas partes ${ }^{6}$. Como essa visão possui uma característica intrinsicamente interdisciplinar, muitos passos importantes na descoberta de propriedades e leis dos fenômenos foram dados em outras ciências, como a biologia e a física (Scharnhorst, 2003).

A análise das redes sociais parte de duas grandes visões do objeto de estudo: as redes inteiras (whole networks) e as redes personalizadas (ego-

\footnotetext{
5 Segundo Wellman (1999 20-22), a Análise Estrutural foi construída através de três grandes tradições: À primeira, de origem britânica, deve-se o desenvolvimento antropológico do conceito de rede social. Nela, os teóricos britânicos realizaram, através de uma perspectiva estrutural-funcionalista, descrições da estrutura social, com um foco na maneira através da qual a cultura prescreve o comportamento considerado válido em grupos muito fechados. A segunda, mais centrada nos Estados Unidos, trabalha fundamentalmente na análise quantitativa e de escopo substantivo (sociometria, por exemplo). Wellman explica que o fundamento principal na teoria dos grafos vem dessa tradição, que buscou na matemática uma forma de analisar as redes sociais. A terceira foca na busca de explicações estruturais para os processos políticos. Os teóricos desta tradição estão centrados no estudo de processos políticos como resultado de laços de troca e dependência entre nações e grupos de interesses (pg. 29). Temos, portanto, uma corrente de viés etnográfico (a primeira), uma de viés quantitativo (a segunda) e uma terceira de viés político. A partir delas, desenvolvem-se as abordagens que hoje são utilizadas no estudo das redes sociais.

${ }^{6}$ As teorias sistêmicas têm sua origem no trabalho do biólogo Luwig Bertalanffy, na década de 30, que estabeleceu seus primados como forma de estudar organismos vivos. Posteriormente, ela tem relações com as teorias da complexidade, da cibernética e da própria comunicação.
} 
centered networks) ([Watts, 2003], [Degenne e Forsé, 1999], [Wellman, 1999, 2001 e 2003] e [Garton et. al, 1997]) O primeiro aspecto é focado na relação estrutural da rede com o grupo social. "As redes, de acordo com esta visão, são assinaturas de identidade social - o padrão de relações entre os indivíduos está mapeando as preferências e características dos próprios envolvidos na rede." (Watts, 2003: 48) O segundo foco estaria no papel social de um indivíduo poderia ser compreendido não apenas através dos grupos (redes) a que ele pertence, mas igualmente, através das posições que ele tem dentro dessas redes. A diferença entre os dois focus está no corpus da análise escolhida pelo pesquisador.

Garton et al. (1997, online) explica que a análise de redes sociais foca principalmente nos padrões de relações entre as pessoas. $\mathrm{O}$ estudo de redes sociais "reflete uma mudança do individualismo comum nas ciências sociais em busca de uma análise estrutural"7. Para ir além dos atributos individuais e considerar as relações entre os atores sociais, a análise das redes sociais busca focar-se em novas "unidades de análise", tais como: relações (caracterizadas por conteúdo, direção e força), laços sociais (que conectam pares de atores através de uma ou mais relações), multiplexidade (quanto mais relações um laço social possui, maior a sua multiplexidade) e composição do laço social (derivada dos atributos individuais dos atores envolvidos). O estudo de redes sociais procura também levar para a sociedade os elementos principais estudados em uma rede, tais como densidade da rede, clusterização ${ }^{8}$ e etc.

Inicialmente, os sociólogos acreditavam que as unidades básicas dessas redes sociais eram as díades, ou seja, as relações entre duas pessoas seriam a menor estrutura relacional da sociedade. E com isso, as relações entre indivíduos que formaria um grupo se dariam de modo mais ou menos

\footnotetext{
7 Tradução da autora: "reflects a shift from the individualism commum in the social sciences towards a structural analysis".

8 Clusters são grupos de nós muito conectados. Em termos de redes sociais, os clusters são considerados grupos sociais coesos. Eles são unidos a outros grupos através de laços individuais de seus membros.
} 
aleatório (Wellman, 1999:31). Um segundo foco de análise para as redes sociais seriam as tríades, de formato triangular9. Nesse modelo, temos duas pessoas com um amigo em comum. Essas duas pessoas têm, deste modo, mais possibilidade de conhecerem-se entre si e de fazerem parte de um mesmo grupo.

Ora, partindo dessa perspectiva, a análise estrutural das redes sociais procura focar na interação como primado fundamental do estabelecimento das relações sociais entre os agentes humanos, que originarão as redes sociais, tanto no mundo concreto, quanto no mundo virtual. Isso porque em uma rede social, as pessoas são os nós e as arestas são constituídas pelos laços sociais gerados através da interação social ${ }^{10}$.

Quando se trata de analisar a interação através da mediação do computador, portanto, é necessário que exista um locus onde essa interação possa e efetivamente aconteça, para que possamos falar em redes geradas por essas ferramentas. ${ }^{11}$

\section{Os Novos Estudos : Modelo de Redes Aleatórias, Modelo de Mundos Pequenos e Modelo de Redes Sem Escalas}

Nos últimos anos, toda uma atenção renovada tem sido dadas às redes complexas através de estudos das áreas da física aplicados às redes, sejam sociais ([Watts , 1999 e 2003,] [Newman, 2004], Adamic e Adar [2004]) e às redes como um todo (Barabási, 2003). Nessas novas perspectivas, foram

\footnotetext{
9 A visão da tríade como elemento estrutural básico de uma organização social remonta aos estudos de Simmel. Entretanto, de acordo com Watts (2003, 36-38), foi o matemático Anatol Rappoport, entretanto, o primeiro a observar tal fenômeno pelo ponto de vista da dinâmica de estruturação de um grupo: Uma triáde tem mais possibilidade de vir a se conhecer no tempo, mostrando como se formariam grupos sociais.

${ }^{10}$ Uma rede social é constituída de nós (indivíduos) conectados por laços sociais (Watts, 2003:75).

${ }^{11}$ Wellman (2001:2) mostra que as redes de computadores são redes sociais porque conectam pessoas."Quando as redes de comunicação mediada por computador conectam pessoas, instituições e conhecimento, elas são redes de suporte social por computador. ". (Tradução da autora: "When computer-mediated communication networks link people, institutions or knowledge, they are computer-supported social networks.")
} 
criados modelos, numa tentativa de explicar características e propriedades das redes.

Watts (2003:28) afirma que a diferença entre os novos estudos de redes e os antigos é que "no passado, as redes foram vistas como objetos de pura estrutura, cujas propriedades estavam fixadas no tempo. Nenhuma dessas assertivas poderia estar mais distante da verdade."12 Para Watts, é preciso levar em conta que nas redes, os elementos estão sempre em ação, "fazendo algo", e que elas são dinâmicas, estão evoluindo e mudando com o tempo. Portanto, a questão crucial para a compreensão dessas redes sociais passava também pela sua dinâmica de sua construção e manutenção. Portanto, a novidade das novas abordagens sobre redes e sua possível constribuição para o estudo das redes sociais está no fato de perceber a estrutura não como determinada e determinante, mas como mutante no tempo e no espaço.

\subsection{Modelo de Redes Aleatórias}

Um dos primeiros estudos sobre grafos e suas propriedades é o do matemático Paul Erdös, em conjunto com Alfred Rényi, também matemático ([Watts, 2003, 1999], Barabási [2003], Buchanan[2002]). Eles escreveram vários trabalhos sobre a teoria dos grafos, dentre os quais se destaca sua teorização sobre "grafos randômicos" (random graphs). Pensando sobre como se formariam as redes sociais ${ }^{13}$, eles demonstraram que bastava uma conexão entre cada um dos convidados de uma festa, para que todos estivessem conectados ao final dela. Erdös e Rényi ainda atentaram para outro fato: Quanto mais links eram adicionados, maior a probabilidade de serem gerados clusters, ou seja, grupos de nós mais conectados. Uma festa, portanto, poderia ser um conjunto de clusters (grupos de pessoas) que de tempos em tempos

\footnotetext{
12 Tradução da autora, No original: "(...)in the past, networks have been viewed as objects of pure structure whose proprierties are fixed in time. Neither os these assumptions could be further from the truth." (grifos do autor)

$13 \mathrm{O}$ trabalho de Erdös e Rényi é considerado fundamentalmente importante porque foi o primeiro a relacionar grafos com redes sociais e tentar aplicar suas propriedades e características para grupos humanos.(Barabási, 2003:19)
} 
estabeleciam relações com outros grupos (rede). Entretanto, como esses nós se conectariam? Eles acreditavam que o processo de formação dos grafos era randômico, no sentido de que esses nós se agregavam aleatoriamente. Dessa premissa, Erdös e Rényi concluíram que todos os nós, em uma determinada rede, deveriam ter mais ou menos a mesma quantidade de conexões, ou igualdade nas chances de receber novos links, constituindo-se, assim, como redes igualitárias (Barabási, 2003: 9-24). Para os autores, quanto mais complexa era a rede analisada, maiores as chances dela ser randômica.

\subsection{Modelo de Mundos Pequenos}

Observando as redes sociais como interdependentes umas das outras, é palusível perceber que todas as pessoas estariam interligadas umas às outras em algum nível. O sociólogo Stanley Milgram, na década de 6o, foi o primeiro a realizar um experimento para observar os graus de separação entre as pessoas. ([Dégene e Forsé, 1999], [Buchanan, 2002]; [Barabasi, 2003] e [Watts, 2003]). Ele enviou uma determinada quantidade de cartas a vários indivíduos, de forma aleatória, solicitando que tentassem enviar a um alvo específico. Caso não conhecessem o alvo, as pessoas eram solicitadas então, a enviar as cartas para alguém que acreditassem estar mais perto dessa pessoa. Milgram descobriu que, das cartas que chegaram a seu destinatário final, a maioria havia passado apenas por um pequeno número de pessoas. Isso indicaria que as pessoas estariam efetivamente, a poucos graus de separação umas das outras Isso indiciaria que estaríamos, efetivamente, vivendo em um "mundo pequeno".

Outra importante contribuição para o o problema da estruturação das redes sociais foi dada pelo sociólogo Mark Granovetter (1973). Em seus estudos, ele descobriu que chamou de laços fracos (weak ties) seriam muito mais importantes, na manutenção da rede social do que os laços fortes (strong ties), para os quais habitualmente os sociólogos davam mais importância. Granovetter mostrou também que pessoas que compartilhavam laços fortes 
(de amigos próximos, por exemplo) em geral participavam de um mesmo círculo social (de um mesmo grupo que seria altamente clusterizado). Já aquelas pessoas com quem se tinha um laço mais fraco, ou seja, conhecidos ou amigos distantes, eram justamente importantes porque conectariam vários grupos sociais. Sem elas, os vários clusters existiriam como ilhas isoladas e não como rede. $\mathrm{O}$ trabalho de Granovetter traz novamente à tona a importância das tríades nas redes sociais. Ora, dois desconhecidos que têm em comum um amigo possuem muito mais chances de virem a se conhecer no tempo do que um padeiro da Argentina e um agricultor chinês. As redes sociais, portanto, não são simplesmente randômicas. Existe algum tipo de ordem nelas.

A partir do experimento de Milgram e das teorias de Granovetter, Ducan Watts e seu orientador, Steven Strogatz (Watts, 1999 e 2003), descobriram que as redes sociais apresentavam padrões altamente conectados, tendendo a formar pequenas quantidades de conexões entre cada indivíduo. Eles criaram um modelo semelhante ao de Erdös e Rényi, onde os laços eram estabelecidos entre as pessoas mais próximas e alguns laços estabelecidos de modo aleatório entre alguns nós transformavam a rede num mundo pequeno (Watts, 2003, 1999). Esse modelo demonstraria que a distância média entre quaisquer duas pessoas no planeta não ultrapassaria um número pequeno de outras pessoas, bastando que alguns laços aleatórios entre grupos existissem ${ }^{14}$.. (Buchanan, 2002) O modelo de Watts e Strogatz é especialmente aplicado para as redes sociais e mostram uma rede mais próxima da realidade das redes sociais: Cada um de nós tem amigos e conhecidos em vários lugares do mundo, que por sua vez, têm outros amigos e conhecidos. Em larga escala, essas conexões mostram a existência de poucos graus de separação entre as pessoas no planeta. Além disso, eles mostraram que bastavam poucos links entre vários

\footnotetext{
${ }^{14}$ Segundo Adamic e Adar (2004:2), é justamente a existência de atalhos entre os indivíduos em uma rede que caracteriza a existência desses mundos pequenos.
} 
clusters para formar um mundo pequeno numa grande rede, transformando a própria rede num grande cluster (Buchanan, 2002).

\subsection{O Modelo das Redes Sem Escalas}

O primeiro problema da teoria dos mundos pequenos de Watts foi explicado por Barabási (2003: 55-64) pouco tempo após a publicação do trabalho. Watts tratava as suas redes sociais como redes aleatórias, ou seja, redes em que as conexões entre os nós (indivíduos) eram estabelecidas de modo aleatório, exatamente como Erdös e Rényi anos antes.

Entretanto, Barabási (2003) demonstrou que as redes não eram formadas de modo aleatório. Ele acreditava que, como os estudos de Watts e Strogatz, bem como de Granovetter tinham apontado, existia uma ordem na dinâmica de estruturação das redes, algumas leis bem específicas. Essa lei, ou padrão de estruturação, foi chamada por Barabási de "rich get richer"- ricos ficam mais ricos. Ou seja, quanto mais conexões um nó possui, maiores as chances de ele ter mais novas conexões. Ele chamou essa característica de preferential attachment ou conexão preferencial: Um novo nó tende a se conectar com um nó pré-existente, mas mais conectado. Essa assertiva implica em outra premissa fundamental: As redes não seriam constituídas de nós igualitários, ou seja, com a possibilidade de ter, mais ou menos, o mesmo número de conexões. Ao contrário, tais redes possuriam nós que seriam altamente conectados (hubs ou conectores) e uma grande maioria de nós com poucas conexões. Os hubs seriam os "ricos", que tenderiam a receber sempre mais conexões. As redes com essas características foram denominadas por ele "sem escalas"15 (scale free).

\footnotetext{
15 O nome "sem escalas" advém de características da representação matemática da rede, que segue uma curva denominada "power law". Matematicamente, as redes sem escala apresentam uma distribuição muito particular, denominada "power law" (uma curva logaritmica que descresce abruptamente a níveis próximos de um mínimo e mantém-se assim, construindo uma longa "cauda". "A distribuição power law implica que uma abundância de nós possui apenas alguns links e uma minoria pequena, mas significativa, tem a grande maioria de links (Barabási, 2001, tradução da autora: "...the power law distribution implies
} 
Scharnhorst (2003, online) discute a existência de uma relação entre os modelos de redes sem escala e de mundos pequenos. De acordo com ela, "algumas vezes, as duas características podem ser atribuídas às redes. Outras vezes, a diferença radical desses dois tipos de rede é destacada"16. O modelo de Barabási e Albert, por exemplo, tem um grau de conectividade muito baixo, já que apenas alguns nós estão altamente conectados, a maioria tem poucos links. Além disso, uma rede sem escalas não é, necessariamente, um mundo pequeno. Já o modelo de Watts e Strogatz tem um grau de conectividade parecido com o de um gráfo aleatório (Erdös e Rényi), mas tem um alto grau de conexão entre os nós. Scharnhorst (2003, online) explica ainda que é preciso que se atente para o fato de que os modelos foram criados sob a forma teórica, em testes realizados em computadores. No mundo real, as redes costumam exibir um grau de distribuição (conectividade) variado, que não necessariamente funcionam num modelo ou outro. "Dependendo da definição teórica escolhida, as propriedades dos dois tipos de rede podem ser encontradas nas redes no mundo real"17, explica.

Entretanto, e quanto às redes sociais? Esses modelos seriam suficientes para dar conta do estudo das redes sociais constituídas via comunicação mediada por computador? Os estudos de Barabási não trabalham especificamente com redes sociais, embora ele explicite que seu modelo é aplicável a todos os tipos de rede. O de Watts e Strogatz é direcionado para redes sociais. Será que os modelos dão conta do fenômeno das redes sociais na Internet?

that there is an abundance of nodes with only few links, and a small-but significant-minority that have a very large number of links.")

16 Tradução da autora:" Sometimes, both characteristics are attributed to networks. Sometimes, the radically different character of these two types of networks is highlighted."

17 Tradução da autora: " Depending upon which theoretical definition is chosen, the properties of both network types in real world networks can be found." 


\section{Redes Sociais na Internet}

Para discutir a validade dos modelos apresentados, trouxemos alguns exemplos de sistemas que poderiam auxiliar a observação das redes sociais na Internet. Esses sistemas funcionam com o primado fundamental da interação social, ou seja, buscando conectar pessoas e proporcionar sua comunicação e, portanto, podem ser utilizados para forjar laços sociais. A partir do exemplo deles, procuraremos observar como a aplicação dos modelos pode ser revelar suficiente ou insuficiente e discutir estes aspectos.

\subsection{Orkut}

Inicialmente, um software denominado Orkut ${ }^{18}$ oferece as primeiras pistas para o desenvolvimento de nossa análise Criado por Orkut Buyukokkten, ex-aluno da Universidade de Stantford e lançado pelo Google em janeiro de 2004, o software é uma espécie de conjunto de perfis de pessoas e suas comunidades. Desenvolvido com base na idéia de "software social"19, ali é possível cadastrar-se e colocar fotos e preferências pessoais, listar amigos e formar comunidades. O Orkut parece oferecer um prato cheio para uma visão das teorias das redes sociais. Mostrando os indivíduos enquanto perfis, é possível perceber suas conexões diretas (amigos) e indiretas (amigos dos amigos), bem como as organizações sob a forma de comunidades ${ }^{20}$. Além disso, existem ferramentas de interação variadas, tais como sistemas de fóruns para comunidades, envio de mensagens para cada perfil, envio de mensagens para comunidades, amigos e amigos de amigos (normalmente utilizadas para spam).

\footnotetext{
18 http://www.orkut.com

19 Sistemas que visam proporcionar conexões entre as pessoas, gerando novos grupos e comunidades, simulando uma organização social.

${ }^{20}$ No Orkut, cada novo membro, ao ser convidado, pode fazer seu perfil, colocando suas informações pessoais e adicionando amigos (que podem ser classificados em "amigos", "conhecidos", "melhores amigos", ou "desconhecidos", mas esta classificação não é disponibilizada para outras pessoas, onde todos aparecem simplesmente como "amigos") e juntando-se a comunidades das mais variadas (interesses, cidade, escolas etc.).
} 
Em princípio, o Orkut parece demonstrar a existência de redes sociais amplas, altamente conectadas, com um grau de separação muito pequeno, exatamente como o previsto no modelo de Watts e Strogatz. É possível, inclusive visualisar os "atralhos" ao visualizar perfis de desconhecidos. Entretanto, com uma observação um pouco mais detalhada, percebe-se que a maioria das "distâncias" entre os membros do sistema é reduzida pela presença de alguns indivíduos, que são "amigos de todo mundo". Esses seriam os hubs, ou seja, pessoas altamente conectadas, com um imenso número de amigos, que contribuem significativamente para a queda da distância entre os indivíduos no sistema. É fácil percebê-los. Enquanto a maioria dos perfis no Orkut no máximo 100 (os menos populares) ou 200 (os mais populares) amigos, algumas pessoas, como o brasileiro Roger Jones ${ }^{21}$ ou o americano Adam Rifkin ${ }^{22}$, acalcançam algo em torno de mil amigos. Exatamente como o modelo de Barabási propõe:

Uma análise mais apurada ainda, observará, no entanto, que a aplicação do modelo de Barabási apresenta alguns problemas.

Inicialmente, constata-se que todos os perfis, no Orkut, podem ser avaliados pelos amigos, onde o perfil recebe qualificações de sensualidade, confiança e interesse. Quanto mais amigos, mais qualificações se recebe. Existe, assim, um interesse muito grande na popularidade, conseguida através de um número de amigos cada vez maior. Mas nem todos esses amigos sào realmente "amigos"23. Isso porque é possível acrescentar quem se deseja como amigo sem que exista qualquer tipo de interação social entre os envolvidos. Basta fazer o pedido e a outra parte aceitar, em uma relação puramente aditiva. A maioria dessas conexões é falsa no sentido de que não apresenta nenhum tipo de interação social e, portanto, não é representativa no sentido

\footnotetext{
${ }^{21}$ http://www.orkut.com/Profile.aspx?uid=10411913000258962067

$22 \mathrm{http}: / /$ www.orkut.com/FriendsList.aspx?uid=10589459868564697084

23 Apesar de ser possível fazer uma classificação entre os "amigos" (como "desconhecido", "conhecido", "amigo", "grande amigo" e "melhor amigo"), essa classificação não é pública. Portanto, alguém classificado como "desconhecido" aparece, para o público, como "amigo".
} 
de demonstrar a existência de uma rede social. Trata-se simplesmente de uma "coleção" de perfis, como podemos perceber a partir do exemplo de Adam Rifkin explicando como se tornar tão popular quando ele: "True top-of-thepop instafrienders randomly invite new people to be friends all the time."24. Há, também, comunidades para auxiliar os que desejam ficar famosos a qualquer custo $^{25}$. E o exemplo do brasileiro Roger Jones, que participa de mais de cinco mil comunidades também demonstra isso: Há comunidades de pessoas discutindo se ele é uma pessoa real, pois jamais interagiu em nenhuma das comunidades em que participa.

Se não existe interação social como pressuposto para o estabelecimento dessas conexões no sistema, será que ele pode ser considerado uma rede social? As conexões no Orkut representam conexões sociais? Ainda que seja possível discutir até que ponto um $h u b$ no Orkut representa um verdadeiro $h u b$ em um grupo social, a verdade é que, para o sistema, essas pessoas são conectores. Elas representam grandes nós que conectam membros de vários grupos isolados, e que, através delas, têm um grau de separação menor entre si. Mas essas redes não poderiam ser consideradas a priori redes sociais, porque em sua formação (ato de adicionar amigos), elas dispensam a interação social, já que esta não é pressuposto para o estabelecimento da conexão. Portanto, eles só funcionam como hubs no sistema do Orkut.

A mesma crítica é salientada por Watts (2003:111-113): no modelo da rede sem escalas, os laços sociais seriam tratados como independente de custo e, portanto, passíveis de ser acumulados pelos hubs. É justamente isso que se observa no Orkut. A junção de novos supostos links - laços sociais- se dá sem custo algum, na medida em que basta adicionar alguém. Não existe envolvimento de troca de capital social, nenhum tipo de envolvimento entre os indivíduos na diade. Do mesmo modo, a exclusão de amigos é indolor e passa praticamente despercebida: Basta deletar da lista.

\footnotetext{
$24 \mathrm{http}$ // $\mathrm{www}$.orkut.com/CommMsgs.aspx? $\mathrm{cmm}=1$ 9319\&tid=11\&pmx $=3 \& p n o=2$ $25 \mathrm{http}: / /$ www.orkut.com/Community.aspx?cmm $=40472$
} 
Ainda assim, poderíamos discutir que a interação social estaria nas comunidades. E que elas as também podem ser hubs, como a comunidade brasileira "Como ou Não Como"26, criada no início de abril deste ano, e atualmente $^{27}$ com quase três mil membros. Conhecida como CoNC, a comunidade tinha por objetivo apresentar perfis de usuários do Orkut que receberiam assim, o julgamento de "como" ou "não como" dos participantes da comunidade. Talvez justamente pela sua proposta, a CoNC imediatamente tornou-se uma das comunidades mais ativas e de crescimento mais rápido do sistema. Essas comunidades também poderiam ser consideradas conectores, porque abrangem um grande número de participantes, conectando entre si, também, outras comunidades ${ }^{28}$. Entretanto, está aí a interação entre as pessoas?

Não parece ser o caso. A comunidade "Como ou Não Como" raramente tem mais do que 50 comentários por tópico, com um pico máximo de 620 comentários. Levando-se em conta que a comunidade tem cerca de três mil membros, não parece haver muita interação. Poder-se-ia argumentar que a interação está dispersa entre os vários tópicos. No entanto, não parece ser o caso. No CoNC, a maioria expressiva de tópicos é apenas um link para o perfil de alguém. Ao que parece, tudo se reduz a um quadro de avisos, em que alguem coloca alguma coisa e quem quiser, se desejar, responde. Existem poucos momentos de diálogo e troca entre os membros das comunidades. $\mathrm{Ou}$ seja, a quantidade de interação não parece proporcional ao tamanho da comunidade. Mesmo assim, a comunidade continua crescendo muito a cada dia.

O que se percebe no Orkut, portanto, é que ele possui hubs que parecem estabelecer-se a partir da ordem de "ricos ficarem mais ricos", na

\footnotetext{
26 http://www.orkut.com/Community.aspx?cmm=34969

27 Em final de maio de 2004, quando este artigo estava em processo de produção.

28 As comunidades também possuem um espaço de "comunidades relacionadas", onde outras comunidades são linkadas.
} 
medida em que as pessoas e comunidades mais populares parecem realmente continuar populares através do tempo e constituir redes sem escalas. No entanto, é preciso notar que existe uma atitude voluntária desses conectores no sentido de aumentar sua popularidade, adicionando novos perfis aleatoriamente à sua lista de amigos. Do mesmo modo, existe também um esforço voluntário das comunidades no sentido de aumentar sua lista de membros, o que se reflete, necessariamente, na sua popularidade. Será que se fosse necessário algum tipo de interação social para a adição dos perfis esses hubs realmente existiriam? Será que, retirados esses hubs, não se observaria uma quantidade média semelhante de amigos entre todos os membros do sistema, o que caracterizaria um modelo de rede igualitária ou de mundo pequeno?

O modelo de Barabási e Albert, portanto funciona no Orkut, mas apenas no nível do software. No nível efetivamente social, ele apresenta problemas. $\mathrm{O}$ primeiro deles é que a existência de hubs sociais toma como pressuposto uma relação social que não tenha custos para as partes. Uma relação social, portanto, na qual as partes envolvidas não precisam dispender tempo, capital social e envolvimento para aprofundar ou manter a conexão entre elas. Isso porque seria impossível para os hubs sociais que conseguissem manter algum tipo de interação com um número tão imenso de conexões. Um laço social pressupõe algum tipo de manutenção, seja ele fraco ou forte. A única diferença entre esses laços é a quantidade de manutenção exigida. Aqui, parece-nos, está outro problema da aplicação do modelo de Barabási para as redes sociais na Internet: ele não pressupõe interação social para o estabelecimento das conexões

A dinâmica do estabelecimento dos laços sociais como a de "ricos que ficam mais ricos" é de difícil análise neste software. Isso porque as pessoas populares atuam voluntariamente no estabelecimento de conexões, não sendo possível falar em "conexão preferencial", na medida em que não são os novos nós que se conectam aos hubs, mas estes que se conectam aos novos nós com 
o objetivo de aumentar a popularidade. O que observamos é que existe algum tipo de "conexão preferencial" unicamente com relação a atitude dos novos nós de procurarem "conhecidos" e tentar adicioná-los como amigos, na tentativa de reproduzir redes sociais do mundo offline.

O modelo de Watts e Strogatz é um pouco mais claro no Orkut. Além de ser possível visualizar os clusters sob a forma de grupos e comunidades, percebe-se como essas são unidas entre si através dos seus membros, que participam também de outros grupos. O Orkut é efetivamente um mundo pequeno. No entanto, os mesmos problemas do modelo de Barabási são visíveis aqui. Não é possível dizer até que ponto essas distâncias sociais entre os indivíduos são realmente válidas porque a maior parte das conexões não pressupõe, novamente, interação social.

O modelo de Erdös e Rényi parece fazer mais sentido neste sistema. Ora, as conexões no Orkut são estabelecidas de modo aleatório pelos hubs. Logo, faz sentido entender que todos os nós têm a mesma chance de receber essas conexões. Seria uma rede mais igualitária. Mas essa assertiva não é inteiramente verdadeira. Embora muitas conexões seja realizadas de modo aleatório, não são todas as conexões que são realizadas assim. Muitos procuram conectar-se a seus amigos no mundo offline. Outros, procuram conectar-se apenas a mulheres bonitas. Outros tantos, a pessoas que admirem profissionalmente. A realidade é que nem todas as conexões são aleatórias, embora muitas delas o sejam.

\subsection{Blogs e Fotologs}

Blogs e Fotologs também apresentam um campo interessante de estudo das redes sociais, na medida em que também possuem uma lista de "amigos" ou "blogs/fotologs" favoritos, bem como mecanismos de interação, tais como ferramenta de comentários, trackbacks e emails. Eles possuem mecanismos semelhantes de funcionamento: As pessoas personalizam a página como desejarem (cores, figuras, fontes e etc.) e colocam posts (blocos de texto ou 
imagens) com uma certa periodicidade. No caso dos fotologs, embora seja possível colocar imagens e texto, o privilégio é para as imagens. Nos blogs, ao contrário, o privilégio é para os textos.

Weblogs e fotologs, portanto, podem representar redes sociais, na medida em que cada weblog ou fotolog representa um indivíduo (ou um grupo) e a exposição de sua individualidade (Recuero, 2003). Entretanto, esses sistemas seriam passíveis de ser compreendidos pelos modelos que explicitamos?

Novamente, aqui será preciso fazer uma pequena dissociação entre os blogs/fotologs enquanto redes sociais e enquanto redes de websites. Um blog ou fotolog pode representar um hub na medida em que possui uma quantidade enorme de incomming links (links que apontam para si) (Barabási, 2003:55-58). Entretanto, neste caso, não poderiam ser considerados hubs de uma rede social, a menos que tais links, de alguma forma, representem algum tipo de conexão entre os blogueiros/fotologueiros. Para tanto seria necessário estudar essas redes a partir do único espaço de interação que o sistema proporcion: os comentários e trackbacks (Primo e Recuero, 2003) Um weblog poderia ser considerado um hub social na medida em que muitas pessoas relacionam-se com o blogueiro através dos comentários. Do mesmo modo, um fotolog pode ser um hub na medida em que possui muitas conexões sociais entre as pessoas que ali interagem.

Nesses sistemas é mais fácil observar a interação, na medida em que ela se dá de maneira repetida: As pessoas efetivamente "conversam" através de comentários ${ }^{29}$. Portanto, cada novo comentário poderia representar uma nova

\footnotetext{
29 Um exemplo retirado do fotolog "CornFlake" <

http://www.fotolog.net/cornflake/?pid=7878405> mostra dois usuários "conversando" nos comentários e referindo-se a inteaçòes sociais anteriores, em outro fotolog. obscure_angel @ 2004-05-23 10:15 said:

Desenho lindoooo!!! Adorei seu estilo!

E sim sim, os desenhos do meu flog são feitos em programinhas de imagem tipo photoshop, direto com o mouse. :)

Kisses.

cornflake@ @2004-05-23 10:15 said:
} 
conexão. Entretanto, não é isso que se observa. Apesar de muitos comentários efetivamente gerarem novas conexões e relações sociais, existem também comentários negativos, no sentido de ocasionar uma retração do indivíduo e, muitas vezes um exílio da comunidade (Recuero, 2004 e Recuero, 2003). Portanto, nem todo o comentário representa uma nova conexão, uma relação aditiva de links. Muitos representam uma relação subtrativa, de dissociação entre nós.

Parece-nos, aqui, que há um novo problema no modelo de Barabási. Reducionista, o modelo da rede sem escalas trata todas as conexões de modo igual, sem diferenciar a qualidade desses links e suas conseqüências para a estrutura da rede social. O modelo de Watts também parece não deixar espaço para que se analise a qualidade as interações, bem com o o de Erdös e Rényi. Preocupados com a dinâmica e as propriedades estruturais das redes, todos parecem ter se esquecido que essas propriedades são intrinsicamente determinadas pelas interações em si, que geram ou destróem conexões. Como Watts (2003) afirmou, não há redes "paradas" no tempo e no espaço. Redes são dinâmicas e estão sempre em transformação.

Nos blogs e fotologs é possível observar a dinâmica de crescimento das redes através dos links. Com os comentários e a interação social decorrente, alguns blogs e fotologs são acrescentados numa lista de links como "blogs amigos" ou "fotologs amigos". Percebe-se que existe uma dinâmica entre as interações através dos comentários até que a pessoa seja considerada "amiga" e acrescida à lista. Muitos tentam barganhar links, numa espécie de troca (Primo e Recuero, 2004).

A existência de "spam" nos comentários de blogs e fotologs famosos indica a possibilidade de que o link dele seja muito valorizado por constituirse em um hub. Esses blogs e fotlogs podem constituir-se como hubs sociais?

thanx $=\mathrm{D}$

mas não existem fotos nessa figura. é desenho "puro", pra variar. ;)

[fiz um esquema de comentários, se acabar o espaço aqui. linque aí do lado] 
A comunicação mediada por computador pode ser muito eficiente no estabelecimento de laços sociais porque facilita sua manutenção. Basta um comentário em um blog ou fotolog, um e-mail ou uma breve conversa no ICQ e já se mantém um laço social existente. Portanto, parece-nos que a CMC pode facilitar a constituição de laços fracos e fortes. Como Granovetter demonstrou, os laços importantes para a manutenção da rede são, justamente, os fracos. Deste modo, a CMC através dos blogs e fotologs pode estar constribuindo para reduzir a distância entre as pessoas, aumentando a clusterização entre os grupos, indo de acordo com o modelo de Watts e Strogatz. Em outras palavras, blogs e fotologs podem estar deixando o mundo ainda menor, seguindo o modelo dos mundos pequenos. Entretanto, como salientamos, esse modelo não proporciona que se observe com rigor o teor dos laços sociais estabelecidos, o teor das interações. Todas são iguais e possuem o mesmo peso para os autores.

O modelo de Barabási, se aplicado a blogs e fotologs, traz alguns pontos importantes para a discussão: Existem algumas evidências de que os novos blogs e fotologs procurem contar-se a blogs e fotologs "famosos" (hubs), no sentido de aumentar suas chances de receber comentários e interagir socialmente. Isso tem uma relação intrínseca com a necessidade de visibilidade (Primo e Recuero, 2004) na Web. As conexões não são feitas de modo aleatório (contrariando, portanto, o modelo de Erdös e Rényi e o de Watts e Strogats): Elas são feitas de modo intencional. As pessoas escolhem a quem desejam se conectar, levando em conta valores específicos (tais como o capital social de um determinado grupo ou mesmo indivíduo). Portanto, os nós não têm a mesma chance de receber comentários e links: não se trata de uma rede igualitária. Poder-se-ia argumentar que trata-se de uma rede sem escalas. Mas o modelo aqui, novamente, torna-se reducionista. Tratando-se de relações intencionalmente estabelecidas, o que elas envolvem? Que características trazem para a rede? Nem todas as interações têm o mesmo peso e a mesma direção. Muitas sequer são construtivas. Nenhum dos 
modelos permite que se analisa, por exemplo, o capital social envolvido em uma relação com uma pessoa muito conectada.

\section{Conclusões e Apontamentos para Discussão}

Como procuramos demonstrar, os modelos de análise das redes propostos por Erdös e Rényi, Watts e Strogatz e Barabási são insuficientes no sentido de perceber as complexidades de uma rede social na Internet. Isso porque esses modelos, apesar de afirmarem sua aplicabilidade para as redes sociais, falham em levar em conta as premissas mais básicas da análise social.

O modelo de Erdös e Rényi, que apresenta uma rede aleatória, tem méritos de ter sido o primeiro a olhar para as redes sociais e sua dinâmica no tempo. Entretanto, as relações entre os indivíduos na comunicaçào mediada por computador não são aleatórias. As pessoas levam em conta diversos fatores ao escolher conectar-se ou não a alguém. Os laços sociais, portanto, são estabelecidos sob prismas muito específicos de interesses comuns de cada nó.

O modelo de Watts e Strogatz, apesar de apresentar uma construção importante, atentando para a clusterização e o valor das pequenas conexões entre grupos para gerar mundos pequenos não observa pontos fundamentais, tais como: a motivação dessas conexões, que nem sempre são feitas de modo aleatório, o teor das interações e laços sociais estabelecidos entre os nós e sua influência na rede.

O modelo de Barabási, o mais mecanicista, traz um importante insight no sentido de prever o mecanismo de construção das redes, o de "ricos mais ricos" e a presença de conectores. Entretanto, o modelo falha em pontos cruciais para o estudo das redes sociais geradas via comunicação mediada por computador. Ele não leva em conta, por exemplo, o custo de manutenção dos laços sociais. Hubs simplesmente acumulam laços, como se a relação entre as pessoas pudesse ser meramente reduzia à uma adição de amigos, sem qualquer custo envolvido. Conseqüentemente, não leva em conta também o 
contexto social e o capital social envolvido em cada interação. Além disso, o mecanismo de "ricos mais ricos" falha na formação de grupos sociais na Internet, pois as pessoas procuram conectar-se a outras por motivos específicos e não simplesmente porque possuem mais conexões. Algumas vezes, o mecanismo parece funcionar no sentido de "fama" de alguns weblogs e fotologs, mas não necessariamente de número de conexões.

Todos os modelos, portanto, apresentam falhas na aplicação às redes sociais na Internet, em grande parte, devido à sua natureza matemática e pouco investigativa do teor das conexões e da não presunção de interação para a constituição do laço social.

\section{Referências Bibliográficas}

1. ADAMIC, Lada; ADAR, Eitan. How to Search a Social Network. Disponível em <http://www.hpl.hp.com/research/idl> Acesso em 23/03/2004.

2. BARABÁSI, Albert-László. Linked. How Everything is Connected to Everything else and What it means for Business, Science and Everydai Life. Cambridge: Plume, 2003.

3. BUCHANAN, Mark. Nexus: Small Worlds and the Groundbreaking Theory of Networks. New York: W.W. Norton e Company, 2002.

4. DEGENNE, Alain e FORSÉ, Michel. Introducing Social Networks. London: Sage, 1999.

5. GARTON, Laura; HARTHORNTHWAITE, Caroline; WELLMAN, Barry. Studying Online Social Networks. Journal of Computer Mediated Communication, V $\quad 3$, issue 1 (1997). Disponível em $<$ http://www.ascusc.org/jcmc/vol3/issue1/garton.html>. Acesso em 12/04/2004.

6. GRANOVETTER, Mark. The Strenght of Weak Ties. American Journal of Sociology, 78,1360-1380 (1973)

7. NEWMAN, M. E. J. Small Worlds. The Structure os Social Networks. Disponível em <http://citeseer.ist.psu.edu/514903.html> (Acesso em 2004) 
8. PRIMO, Alex; RECUERO, Raquel. Hipertexto Cooperativo: Uma Análise da Escrita Coletiva a partir dos Blogs e da Wikipédia. Trabalho apresentado no VII Seminário Internacional de Comunicação. Porto Alegre: PUC/RS, 2003. 9. . Co-Links: Proposta de uma nova tecnologia para a escrita coletiva de links multidirecionais. Trabalho apresentado no GT de Tecnologias da Informação e da Comunicação da COMPÓS. São Bernardo do Campo: 2004.

10. SCHARNOHORST, Andrea. Complex Networks and the Web: Insights From Nonlinear Physics. Journal od Computer Mediated Communication, V. 8, issue $\quad 4$ 4 $2003 \quad$ Disponível em <http://www.ascusc.org/jcmc/vol8/issue4/scharhorst.html>. Acesso em 23/03/2004.

11. TINDALL, D. B; WELLMAN, Barry. Canada as Social Structure: Social Network Analysis and Canadian Sociology. Journal of Canadian Sociology, 2001. Disponível em <http://www.chass.utoronto.ca/ wellman/publications/cansocstr/Can_NetFinal-30Apo1.htm > . Acesso em 22/03/2004.

12. WATTS, Duncan J. Six Degrees. The Science of a Connected Age. New York: W. W. Norton \&Company, 2003.

13. . Small Worlds. The dynamics of Networks between Order and Randomness. New Jersey: Princetown University Press, 1999. 14. WELLMAN, Barry et. al. The Social Affordances of Internet for Networked Individualism. In: Journal of computer Mediated Communication, V. 8 Issue 3, (2003). Disponível em <http://www.ascusc.org/jcmc/vol8/issue3/wellman.html>. Acesso em 23/03/2004.

15. WELLMAN, Barry. Physical Place and CyberPlace: The Rise of Personalized Networking. Fevereiro de 2001. Disponível em: <http://www.chass.utoronto.ca/ wellman/publications/individualism/ijurr3 a1.htm> 
16. . Structural Analysis: from method and metaphor to theory and substance. In : WELLMAN B. e BERKOWITZ, S. D. (editores). Social Structures: A Network Approach. Cambridge: Cambridge Press, 1998 